\title{
Efficacy of Explicit Instruction of Discourse Connectives for Verbal Communication
}

\author{
a Tayyabba Yasmin, ${ }^{\mathrm{b}}$ Aniqa Rashid, ${ }^{\mathrm{c}}$ Samina Ali Asghar \\ ${ }^{a}$ Associate Professor, University of Education, Lahore, Pakistan \\ Email: tayyaba.yasmin@ue.edu.pk \\ ${ }^{\mathrm{b}}$ Assistant Professor, National University of Modern Languages Faisalabad Campus, Pakistan \\ Email: ansrashid@numl.edu.pk \\ ${ }^{\mathrm{c}}$ Lecturer, University of Education, Lahore, Pakistan \\ Email: saminaali53@yahoo.com
}

\begin{tabular}{l}
\hline ARTICLE DETAILS \\
\hline History: \\
Accepted 30 July 2021 \\
Available Online September 2021
\end{tabular}

Keywords:

Explicit, Instruction, Discourse

Markers, Connectives,

Communication

JEL Classification:

L63, L69

DOI: $10.47067 /$ real.v4i3.178

\begin{abstract}
Discourse connectives are fundamental components of verbal communication due to their significant role in the creation of coherence, expression of emotive and mental states, and in the navigation of turntaking (Villegas, 2019). This research study was conducted to explore the effect of explicit instruction of discourse connectives on the communication skills of English language learners. The sample of 40 students was taken and divided into two groups i.e. control and experimental group. Pretest and posttest were conducted to evaluate the proficiency level of students. IELTS interactive test was employed as an instrument to analyze the scores of pretest and posttest. The experimental group was taught with the help of an explicit method of instruction for thirty days whereas no explicit instruction of discourse markers was received by the control group. The findings of the research revealed that the explicit instruction of teaching was considered more effective for teaching discourse markers as compared with the traditional mode of teaching. The findings of the present study call for the reinforcement of discourse connectives employing explicit teaching strategies for improving the verbal communication of ESL learners.
\end{abstract}

(C) 2021 The authors. Published by SPCRD Global Publishing. This is an open access article under the Creative Commons AttributionNonCommercial 4.0

Corresponding author's email address: tayyaba.yasmin@ue.edu.pk

\section{Introduction}

Discourse connectives have been considered as a significant feature of communication. The use of discourse connectives in verbal communication makes our speech more coherent and organized. Conversely, the lack of these cohesive devices creates hitches in communication. Most of the earlier studies conducted in the area of discourse have only concentrated on learning the passive skills of English and productive skills are almost neglected. Discourse connectives can also be utilized to attach the sentences with their context (Redeker, 1990). The context can be interpreted as a shared ground of participants involved in a conversation. Heeman (1999) suggests that these cohesive devices can be employed to perform various functions for instance to hold a turn, sign of acceptance, speech repair, 
and to point out a disturbance in the organization of discourse. These connectives help the speaker to explicate the main idea and organize the lexical components. Das and Taboada (2018) assert that the use of discourse connectives excels the process of text comprehension.

The significance of discourse connectives as a prominent facet of spontaneous conversation cannot be ignored (Fox \& Schrock, 2002). The connectives are deemed a crucial feature of natural oral discourse. These connectives operate on various planes i.e. social, cognitive, psychological, and interactional levels (Villegas, 2019). Due to the crucial role of discourse markers in communication, it is assumed that these connectives also need special consideration in ESL classrooms. In our Pakistani context, discourse connectives have hardly been a component of the syllabus despite of their significant role in communication. The present research examines the effect of two different teaching methodologies on the verbal skills of learners.

Objectives of this study are:

1. To explore the impact of explicit teaching of discourse connectives on verbal communication of ESL learners.

2. To compare the efficacy of traditional and explicit methods for the instruction of discourse connectives.

The present study seeks to answer the following research questions:

1. Does the explicit teaching of discourse connectives have an effect on verbal communication of ESL learners?

2. Is there any association between the explicit teaching of discourse connectives on the verbal communication of ESL learners?

\section{Literature Review}

The use and role of discourse markers have been explored by various linguists and scholars (Schourop, 1985; Schiffrin, 1987; Fraser, 1990). They have presented similar views regarding the definitions of discourse markers that various fragments of discourse are linked with the help of these connectives. Different terminologies have been employed for discourse markers such as discourse connectives, pragmatic markers, and discourse operators. Schiffrin (1987) defines these connectives as components that are sequentially reliant and help to bracket the various sections of oral discourse. Fraser (1999) asserts that these connectives may include prepositional expressions and adverbs to link the sentences and paragraphs.

A variety of linguistic echelons of discourse markers have been elaborated by Fraser (1999). At the phonological level, discourse markers can be reduced or shortened. A few phrases which are repeatedly employed to attain any specific purpose in communication are not transcribed with the omission of some central sounds (Ostman, 1982). Only monosyllabic markers are unstressed. However, at the morphological level, discourse markers may be polysyllabic i.e. before, nevertheless, furthermore, and consequently. They also may involve complete expressions like as a consequence or that is to say. At a syntactic level, discourse markers can be included in the categories of prepositions, coordinate conjunctions, adverbs, subordinate conjunctions, and prepositional phrases. Der (2010) states that connectives are weakly connected to the components of the major clause; only a few have their structure at the syntactic level.

At the semantic level, these markers do not add anything to the propositional content of an utterance (Schiffrin, 1987). However, the functions of these discourse connectives have been explicated 
according to various approaches and perspectives.

Table.1 Functions of Discourse Markers (Brinton, 1996)

\begin{tabular}{|l|l|}
\hline Frame Markers (Opening) & to start the discourse (getting attention of the listener) \\
\hline Frame Markers (Closing) & to close the conversation \\
\hline Turn Takers & to hold the floor \\
\hline Fillers & to help the speakers to continue the discourse \\
\hline Switchers of Topic & to specify a new topic or change in the existing topic \\
\hline Indicators of information & to indicate old or new information \\
\hline Sequence Markers & to point out sequential order \\
\hline Repair Markers & to repair the conversation \\
\hline
\end{tabular}

Van Dijk (2013) has also highlighted this notion by asserting that the major role of discourse connectives is to perform pragmatic functions. However, these markers have been considered multifunctional working on various linguistic planes concurrently with no exclusive purpose (Lutzky, 2021).

Students should be given appropriate instruction of discourse devices by employing various strategies to allow them to perform various tasks and activities (Hyland, 2005). Martinez (2004) examined the role of discourse connectives for the instruction of expository writing of Spanish students. The results exhibited a significant relationship between the use of discourse connectives and the scores of students. The expository essays of Spanish students with extensive use of contrastive, topic-related, and elaborative discourse connectives achieved higher scores. In another research study, the effect of explicit teaching of discourse connectives on the writing skill of EFL learners was determined by Dastjerdi and Shirazad (2010). The results of their study disclosed that explicit teaching of discourse connectives enhanced the writing skill of EFL learners. However, researches on exploring the impact of explicit instruction on oral skills are rarely available in the Pakistani context.

\section{Methods}

The nature of this study was experimental. Data was collected from university students. The current study involved two groups of learners i.e. experimental and the control group. 40 ESL learners were selected by using simple random sampling. 20 students were allotted to each group. Both groups were taught by the same instructor. Before the commencement of the experiment, a pretest was conducted of both groups. IELTS interactive test was borrowed and employed as an instrument. No instruction regarding discourse markers was received by the students before the pretest. Two different approaches of instruction were utilized. The instructional material was based on similar objective for both the group. The selection of discourse connectives was based on their frequency and functions by adopting Fung and Carter (2007). 
Table. 2 Paradigm of Discourse Connectives (Fund \& Cater, 2007)

\begin{tabular}{|l|l|l|l|}
\hline Indicating reason & $\begin{array}{l}\text { Denoting shared } \\
\text { information }\end{array}$ & $\begin{array}{l}\text { Opening as closing of } \\
\text { conversations }\end{array}$ & $\begin{array}{l}\text { Representing listener's } \\
\text { evaluation }\end{array}$ \\
\hline $\begin{array}{l}\text { Examples: But, yet, } \\
\text { contrast, however }\end{array}$ & $\begin{array}{l}\text { Examples: you know, } \\
\text { see, listen }\end{array}$ & $\begin{array}{l}\text { Examples: let's start } \\
\text { right, alright, let me } \\
\text { conclude }\end{array}$ & Example: You know \\
\hline $\begin{array}{l}\text { Expressing } \\
\text { coordination }\end{array}$ & Expressing attitudes & $\begin{array}{l}\text { Representing shifts in } \\
\text { topics }\end{array}$ & Indicating reformulation \\
\hline $\begin{array}{l}\text { Examples: And } \\
\text { Referring } \\
\text { disjunction } \\
\text { Examples: Or }\end{array}$ & $\begin{array}{l}\text { Examples: Really, well, } \\
\text { absolutely, I think, sort } \\
\text { of }\end{array}$ & $\begin{array}{l}\text { Examples: well, now, } \\
\text { so }\end{array}$ & $\begin{array}{l}\text { Examples: in } \\
\text { word, I mean }\end{array}$ \\
\hline $\begin{array}{l}\text { Signifying } \\
\text { comparisons } \\
\text { Examples: } \\
\text { Similarly, like }\end{array}$ & $\begin{array}{l}\text { Representing responses } \\
\text { Examples: Okay, right, } \\
\text { yes, yeah sure }\end{array}$ & $\begin{array}{l}\text { Referring } \\
\text { continuation of topic } \\
\text { Examples: cos, yeah }\end{array}$ & $\begin{array}{l}\text { Expressing explanation } \\
\text { Examples: Like, I mean }\end{array}$ \\
\hline
\end{tabular}

The explicit instructional method involved activities like dialogues, role-playing, and pair work. On the other hand, learners of the control group worked independently without any practice. Time duration of the experiment was thirty days. Both groups were taught by the same teacher. After the intervention, a posttest of both groups was conducted to measure the proficiency of the experimental and control group. Tests were conducted before the instructional input and immediately after it. These tests were further recorded into audio files. The tests of both groups were marked according to the standardized criteria to evaluate their discourse management and verbal ability.

\section{Data Analysis}

Data was analyzed by employing SPSS software. The mean difference of scores was measured by applying inferential statistics i.e. independent sample t-test and paired t-test.

Table: 3 Scores of Pretest of Control and Experimental Group

\begin{tabular}{|c|c|c|}
\hline & & 20 \\
\hline Experimental Group (Score) & 4.12 & 20 \\
\hline Control Group (Score) & 4.15 & 20 \\
\hline
\end{tabular}




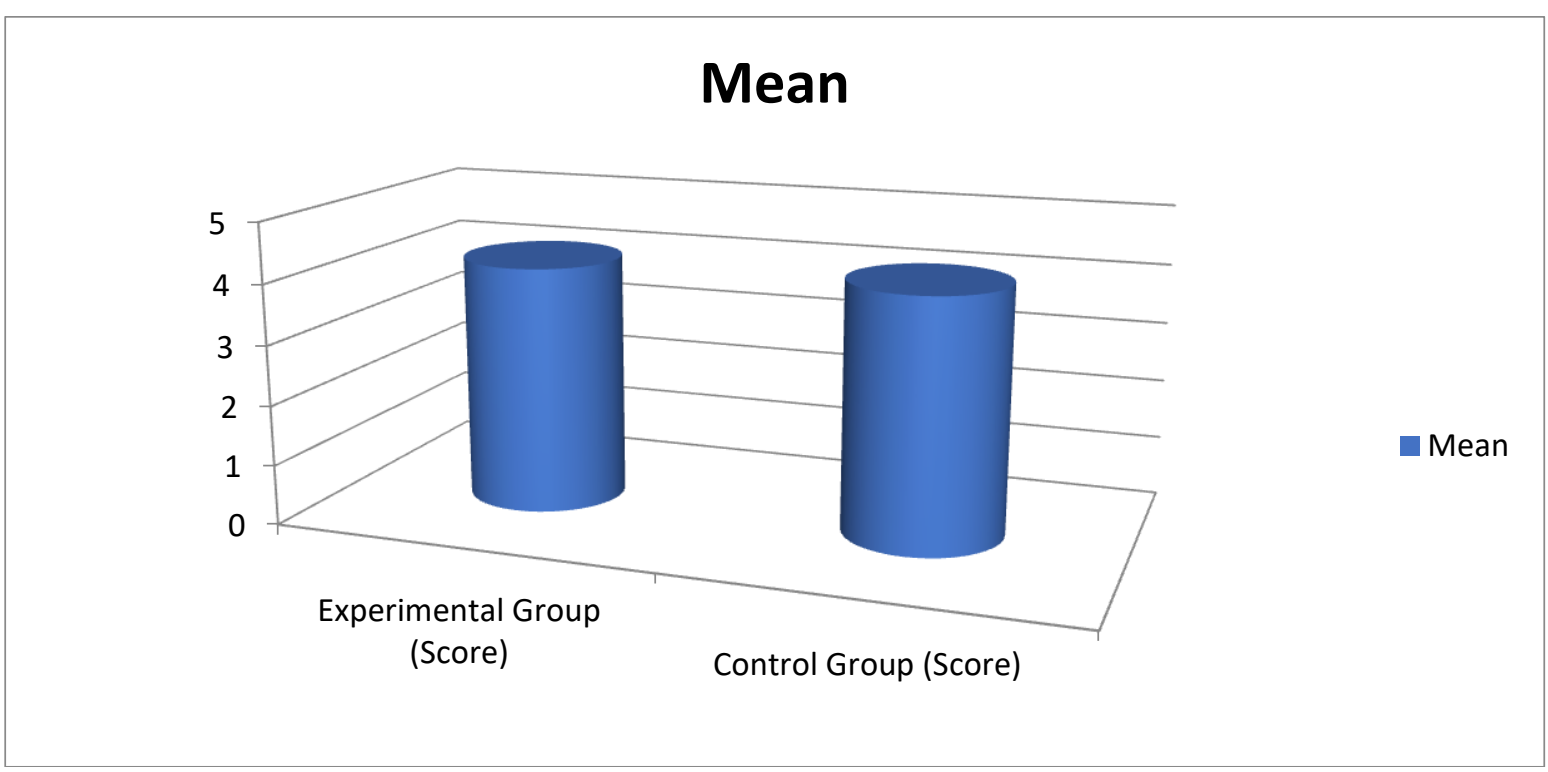

Figure.1 Comparisons of Mean Scores of Pretest of Control and Experimental Group

Data analysis revealed that both the groups were found almost equal regarding their proficiency in discourse management in the pretest. No significant difference $(\mathrm{x}$ Exp=4.12, $\mathrm{x}$ cont $=4.15, \mathrm{t}=-. \mathrm{og}$, $\operatorname{sig}=.928$ ) was found in both the group before the intervention of independent variable.

Table. 5 Scores of Control and experimental group in Posttest (Independent Sample t-test)

\begin{tabular}{|c|c|c|c|}
\hline & Group & N & Mean \\
\hline Posttest & experimental group & 20 & $4 \cdot 30$ \\
\hline & control group & 20 & 2.35 \\
\hline
\end{tabular}




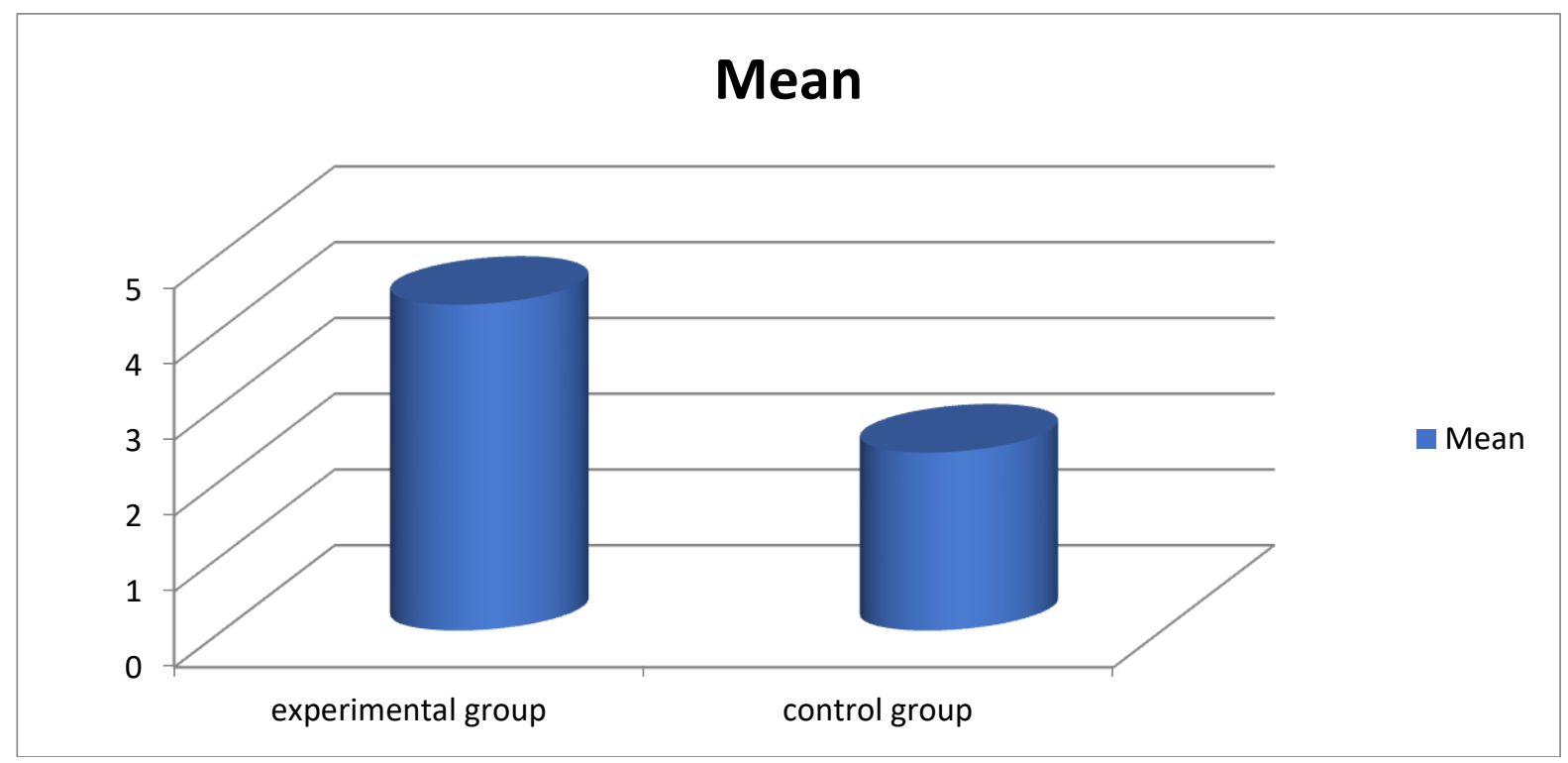

Figure: 2 Comparisons of Mean Scores of Posttest Control and Experimental Group

Table.5 illustrated that a significant difference $(\mathrm{x} \operatorname{Exp}=4.30, \mathrm{x}$ cont $=2.35, \mathrm{t}=-.9 .89$, sig=.ooo) were found in the scores of the posttest of the experimental and control group regarding their proficiency level of discourse management. Data analysis exposed that the students who received explicit instruction outperformed than the participants of the control group. The results of the posttest exhibited that the experimental group employed more discourse connectives in their interactive discourse in comparison with their performance of the pretest.

\section{Discussion}

It was observed from the data analysis that both groups were found almost equal according to the scores of pretest with regard to their proficiency in verbal communication. Moreover the scores of both tests of control and experimental groups were analyzed to explore their performance. The difference between mean scores of the two groups was .ooo (level). It means that there was substantial difference between mean scores of pretest and posttest of experimental group concerning their proficiency of using discourse markers. The findings of this study are also in consonance with a study conducted by Jones and Carter (2013) in which explicit framework facilitated in increasing the use of discourse connectives and greatly influenced the verbal communication of the experimental group. It can be inferred that traditional teaching has not been effective for enhancing the communication skills of the control group. Similar findings have also been observed in a previous study (Llantada, 2005) which was conducted to investigate the effects of the teaching of discourse markers on oral skills of university students and found that these strategies have enhanced the communication skills of students.

\section{Conclusion}

The findings of the study demonstrated that explicit framework of teaching discourse connectives facilitated ESL learners in enhancing their verbal communication. It is evident from the results of the study that explicit instruction improved the scores of the posttest of the experimental group. It is concluded that the explicit framework of discourse connectives had a greater effect on the verbal communication of ESL learners. It can also be implied that explicit teaching of discourse 
connectives is inevitable for enhancing the verbal communication of second language learners. It is recommended that ESL instructors, researchers, and language practitioners should pay heed to discourse connectives as a crucial facet of oral communication. The findings of the study will also provide valuable insights for creating awareness of discourse markers for improving verbal communication. This study also suggested a re-conceptualization of existing teaching practices with an explicit framework of instruction.

\section{References}

Brinton, L. (1996). Pragmatic markers in English: Grammaticalization and discourse functions. Berlin/NewYork: Mouton de Gruyter.

Das, D. \& Taboada, M. (2018). Signalling of Coherence Relations in Discourse, beyond Discourse Markers. Discourse Processes 55 (8): 743-770.

Dastjerdi, H. V. \& Shirzad, M. (2010). The Impact of Explicit Instruction of metadiscourse Markers on EFL Learners' Writing Performance. The Journal of Teaching Language Skills (JTLS), Vol, 2.

Dér, C. (2010). On the status of discourse markers. Acta Linguistica Hungarica, 57(1), 3-28.

Fox, J., E. Schrock. (2002). Basic meanings of you know and I mean. Journal of Pragmatics 34, 727-747.

Fraser, Bruce, 1990. An approach to discourse markers. Journal of Pragmatics 14, 383-395.

Fraser, B. 1999. What Are Discourse Markers? Journal of Pragmatics 31 (7): 931-952.

Fung, L and R, Carter. (2007). Discourse markers and spoken English: Native and learner use in pedagogic settings. Language Teaching Research 11, 2, 159-182.

Heeman, P and J, Allen. (2000). Speech repairs, Intonational phrases and discourse markers: Modeling speakers'utterances in spoken dialogue.Computational Linguistics, 25, 4. 80-122.

Jones, C., \& Carter, R. (2013). Teaching spoken discourse markers explicitly: A comparison of III and PPP. International Journal of English Studies, 14(1), 37-54.

Llantada, C. P. (2005). Instruction and interaction in an American lecture class, observation from a corpus. The ESPecialist, Vol., 2. (205-227).

Lutzky, U. (2012). Discourse Markers in Early Modern English. Amsterdam: John Benjamins Publishing Co.

Martinez, A. C. L. (2004). Discourse markers in the expository writing of Spanish university students. IBERICA, 8, 63-80.

Ostman, J. -O. 1982. 'You know: A discourse functional approach'. Pragmatics and

Beyond 11-. 7. Amsterdam: Benjamins.

Redeker, G. (1990). 'Ideational and pragmatic markers of discourse structure'. Journal of Pragmatics 14/3: 367-381.

Schiffrin, D. (1987). Discourse Markers. Cambridge: Cambridge University Press.

Schourup, L. C. (1985). Common Discourse Particles in English Conversation. New York: Garland

Van Dijk, T.A. (2013). YouTube Lecture. Published on Apr 25, 2013. https://www.youtube.com/watch?v=sxfc-WJRKEM

Villegas, C. L. (2019). Discourse Markers and Pragmatic Markers in Spoken and Written Everyday Life. https://doi.org/https://doi.org/10.13140/RG.2.2.33992.57602 